\title{
Evaluation and Comparison of Two Selective Extraction Procedures for Heavy Metal Speciation in Sediments
}

\author{
Carmela Ianni ${ }^{\dagger}$, Nicoletta Ruggieri, Paola Rivaro, and Roberto Frache \\ Dipartimento di Chimica e Chimica Industriale-Sezione di Chimica Analitica ed Ambientale-Università \\ di Genova, Via Dodecaneso 31, 16146-Genova, Italy
}

\begin{abstract}
Two sequential extraction procedures (the former proposed by the Standard, Measurements and Testing-SM\&T-program of European Union and the latter derived from those of Tessier and Forstner with various modifications) have been compared, by analyzing a reference material (CRM 601) certified for the content of heavy metals in the three solutions resulting from the SM\&T procedure. Scanning electron microscopy-energy dispersive X-ray analysis (SEM-EDX) was used to evaluate the composition of the residues after various extractions. Reliable results, both in terms of precision and accuracy, were obtained for the first two steps of the SM\&T scheme. As regards the third step, because it was modified during this work, a direct comparison of our results with those certified is not possible. SEM analysis confirmed that the scheme previously used in the laboratory was more aggressive compared to the SM\&T procedure, which has also the advantage that the only CRM available for metal partitioning in sediments is certified using this method.
\end{abstract}

(Received April 27, 2001; Accepted August 3, 2001)

\section{Introduction}

It is now widely accepted that, to assess the role of sediments as sinks or sources for heavy metals, the measurement of the total content must be integrated with the determination of metal partitioning among the different sediment phases. In fact, it is necessary to obtain information on the potential availability of metals (whether toxic or essential) to biota under various environmental conditions. ${ }^{1}$ The behavior of metals and their availability strictly depends on their chemical form, and thus on their speciation. Therefore, the ability to determine the chemical form or kind of association with different mineralogical phases in marine or freshwater sediments has become increasingly important. To date, it has generally been accepted that the most appropriate methods to evaluate solid speciation are selective sequential extraction procedures, ${ }^{2}$ which are widely used to assess the long-term emission potential of pollutants and to study the distribution of pollutants among the geochemical phases. ${ }^{3}$ Although the reagents used in sequential extraction procedures may be insufficiently specific to exclusively dissolve the "target" phases, ${ }^{1}$ and the obtained results can vary widely when different extraction schemes ${ }^{4}$ and experimental conditions ${ }^{5,6}$ are used, useful information has been gained from such studies. In fact, a large number of sequential extraction methods have been studied and reported, many of which are variants of the Tessier procedure. ${ }^{7}$

Recently, studies on selective extractions have received new emphasis with the availability of a sediment reference material, certified for the metal content in the acetic acid extractable, acidic hydroxylamine extractable and acidic hydrogen peroxide extractable fractions, by the SM\&T program of the European Union, ${ }^{8}$ following a less aggressive procedure that was

$\dagger$ To whom correspondence should be addressed.

E-mail: ianni@chimica.unige.it previously tested and optimized during various intercomparison exercises. ${ }^{9,10}$ The increasing performances of the analytical techniques used for element determination in an extract, together with increasing evidence that exchangeable metals better correlate with plant uptake, has led extraction methods to evolve towards the use of progressively less aggressive solutions. ${ }^{11}$

The availability of a selective extraction method which seems more suitable for environmental research and of a CRM which permits one to verify the performances of laboratories is very challenging for researchers working in speciation fields. This work compares the results obtained when using two different schemes on the sediment reference material (CRM 601), certified for the metal content in three solutions resulting from the SM\&T procedure. ${ }^{8}$ The aim, after checking the analytical performance of the laboratory, is to evaluate the feasibility of the new three-step protocol designed by SM\&T for environmental studies, even through a comparison with the method used previously in our laboratory. This is a scheme derived from the Tessier et al. ${ }^{7}$ and the Förstner et al. ${ }^{12,13}$ procedures and modified during the past years in our laboratory. ${ }^{14}$

In order to check the efficiency and selectivity of the two procedures, the sediment and residues after extractions have been subjected to SEM-EDX analysis for the detection of characteristic particles. Microchemical techniques have been used by other workers to study selective extractions, ${ }^{5,15,16}$ or together with them to better characterize the solid phases; ${ }^{17}$ they were also very useful in our previous studies regarding the optimization of sequential extractions for applications to particulate matter. ${ }^{18,19}$ 


\section{Experimental}

\section{Instrumentation}

The determinations of $\mathrm{Zn}, \mathrm{Ni}, \mathrm{Cu}, \mathrm{Fe}$ and $\mathrm{Pb}$ were carried out with an inductively coupled plasma atomic emission spectrometer (ICP-AES) Jobin-Yvon 24. Cd was determined by electrothermal atomization atomic absorption spectroscopy (ETA-AAS) (Varian Spectra A300 spectrometer with a Zeeman-effect background correction and autosampler Varian Model 96). For sample digestion, a CEM MDS 2000 microwave oven was used. The digestion vessels were made of PTFE.

SEM-EDX analyses were performed with a Leo Stereoscan 440 scanning electron microscope, equipped with an energy dispersive, $120 \mathrm{eV}$ resolution, germanium detector (Oxford Link-Gem).

\section{Pseudototal attack}

The pseudototal metal content was determined by digesting the samples with aqua regia in a microwave oven with the following program: $5 \mathrm{~min}$ at $250 \mathrm{~W}$ power, $5 \mathrm{~min}$ at $320 \mathrm{~W}$ power and $10 \mathrm{~min}$ at $380 \mathrm{~W}$ power. The digests were filtered, transferred in polyethylene containers and stored at $4^{\circ} \mathrm{C}$ until analysis. The residue remaining after the last step of the sequential extractions was digested similarly. Blank vessels, containing acid but no sample, were processed with the samples and showed no significant contamination. The accuracy of the procedure was checked with CRM 277 (estuarine sediment) from BCR.

\section{Sequential extraction procedures}

Procedure A $(S M \& T)$. The procedure used in this study was partly different from the SM\&T protocol, ${ }^{8}$ whereas in our procedure the extracts are made up to $50 \mathrm{ml}$ after adding $1 \mathrm{ml}$ of nitric acid $(65 \%)$ for better preservation. Moreover, in the original scheme, the third step is carried out at $85^{\circ} \mathrm{C}$ in a water or sand bath, while in our work microwaves are used.

Step 1. Exchangeable and acid soluble: Forty milliliters of $0.11 \mathrm{M}$ acetic acid were added to $1 \mathrm{~g}$ of sediment in polyethylene centrifuge tubes, which were shaken overnight (16 h) at room temperature. The extracts were separated from the residues by centrifugation. The residues were rinsed with 0.11 $\mathrm{M}$ acetic acid and the rinsing solutions were added to the extracts. After the addition of $1 \mathrm{ml}$ of nitric acid (65\%), the solution was made up to $50 \mathrm{ml}$, transferred into clean polyethylene containers and stored at $4{ }^{\circ} \mathrm{C}$ until analysis. The residue was rinsed with Milli-Q water (Millipore) prior to the next step.

Step 2. Easily reducible phase: Forty milliliters of $0.1 \mathrm{M}$ hydroxylamine hydrochloride, adjusted to $\mathrm{pH} 2$ with nitric acid (65\%), were added to the residue and the same procedure as mentioned above was carried out.

Step 3. Oxidizable phase: The residue was put in a microwave Teflon vessel and, after carefully adding $10 \mathrm{ml}$ of hydrogen peroxide $(8.8 \mathrm{M})$, left at room temperature for $1 \mathrm{~h}$ with occasional manual shaking. The samples were then treated at $50^{\circ} \mathrm{C}$ in an ultrasound bath for $2 \mathrm{~h}$. A further aliquot of $10 \mathrm{ml}$ of hydrogen peroxide $(8.8 \mathrm{M})$ was added and the vessels were heated in a microwave oven with the following program: 4 steps at $120 \mathrm{~W}, 4$ steps at $180 \mathrm{~W}$ and 2 steps at $250 \mathrm{~W}$ power, each step of $2 \mathrm{~min}$, with a pause of about $15 \mathrm{~min}$ between every step. After cooling, $20 \mathrm{ml}$ of $2 \mathrm{M}$ ammonium acetate adjusted to $\mathrm{pH} 2$ with nitric acid (65\%) were added and the samples were transferred in polyethylene centrifuge tubes, which were shaken
Table 1 Detection and quantification limits for analytes in SM\&T sequential extraction steps and $20 \%$ aqua regia $(\mu \mathrm{g} / \mathrm{g})$

\begin{tabular}{llcccc}
\hline \multirow{2}{*}{$\mathrm{Zn}$} & & Step 1 & Step 2 & Step 3 & Aqua regia \\
\hline \multirow{2}{*}{$\mathrm{Pb}$} & L. O. D. & 0.43 & 0.15 & 0.18 & 0.09 \\
& L. O. Q. & 1.30 & 0.50 & 0.60 & 0.30 \\
& L. O. D. & 0.30 & 0.58 & 1.30 & 0.35 \\
$\mathrm{Ni}$ & L. O. Q. & 1.00 & 1.93 & 4.33 & 1.17 \\
$\mathrm{Ni}$ & L. O. D. & 0.15 & 0.63 & 0.63 & 0.57 \\
$\mathrm{Cd}$ & L. O. Q. & 0.50 & 2.10 & 2.10 & 1.90 \\
& L. O. D. & 0.01 & 0.03 & 0.04 & 0.06 \\
$\mathrm{Fe}$ & L. O. Q. & 0.03 & 0.10 & 0.13 & 0.20 \\
& L. O. D. & 0.50 & 0.77 & 2.85 & 0.60 \\
$\mathrm{Cu}$ & L. O. Q. & 1.67 & 2.57 & 9.50 & 2.00 \\
& L. O. D. & 0.40 & 0.31 & 0.31 & 0.30 \\
& L. O. Q. & 1.33 & 1.03 & 1.03 & 1.00 \\
\hline
\end{tabular}

overnight (16 h) at room temperature. After centrifugation, the procedure was carried out as for steps 1 and 2. This step is the result of a series of preliminary experiments which indicated the best working conditions.

\section{Procedure B (used previously in the laboratory).}

Step 1. Exchangeable and bound to carbonates: Forty milliliters of $1 \mathrm{M}$ ammonium acetate ( $\mathrm{pH}$ 5) were added to $2.5 \mathrm{~g}$ of sediment in polyethylene centrifuge tubes, which were shaken overnight at room temperature. The extracts were separated from the residues by centrifugation. The residues were rinsed with ammonium acetate $(1 \mathrm{M})$ and the rinsing solutions were added to the extracts. After the addition of $1 \mathrm{ml}$ of nitric acid $(65 \%)$ for better preservation, the solution was made up to $50 \mathrm{ml}$, transferred into clean polyethylene containers and stored at $4^{\circ} \mathrm{C}$ until analysis. The residue was rinsed with Milli-Q water prior to the next step.

Step 2. Reducible phase: Forty milliliters of 1 M hydroxylamine hydrochloride and $25 \%$ acetic acid (1:1) were added to the residue and the same procedure as mentioned above was carried out.

Step 3. Oxidizable phase: The residue was put in a microwave Teflon vessel and, after the addition of $12 \mathrm{ml}$ of $8 \mathrm{M}$ nitric acid, heated in a microwave oven with the following program: $5 \mathrm{~min}$ at $250 \mathrm{~W}$ power, $10 \mathrm{~min}$ at $380 \mathrm{~W}$ power and $15 \mathrm{~min}$ at $470 \mathrm{~W}$ power. After centrifugation, the residue was rinsed with nitric acid, the rinsing solution added to the extracts and made up to $50 \mathrm{ml}$ with Milli-Q water.

\section{Metal analyses}

All of the solutions were analyzed for Cd using ETA-AAS and the standard addition method for calibration. The other metals were determined by ICP-AES and the external standard method, using matrix-matching calibrants. Sequential extraction reagent blanks showed no detectable contamination. Table 1 gives the limits of detection (LOD) and of quantification (LOQ), calculated as 3 and 10 times, respectively, the blank standard deviation.

\section{SEM-EDX analyses}

Morphological and electron-probe analyses were conducted on the sediments before and after the various attacks. The particles (about 400-500 for each sample) were classified as follows:

- Organic (1): particles with no peculiar morphological characteristics, with low and irregular signals producing the lines of $\mathrm{C}$ and $\mathrm{O}$. 
a

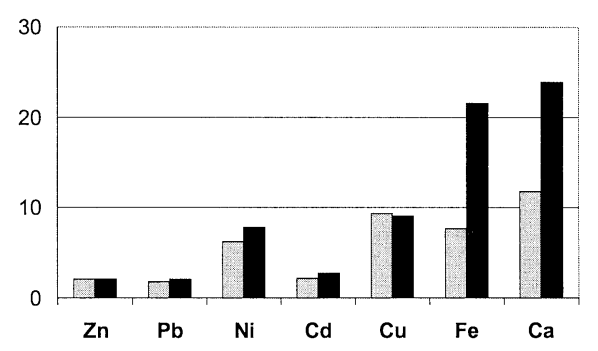

b

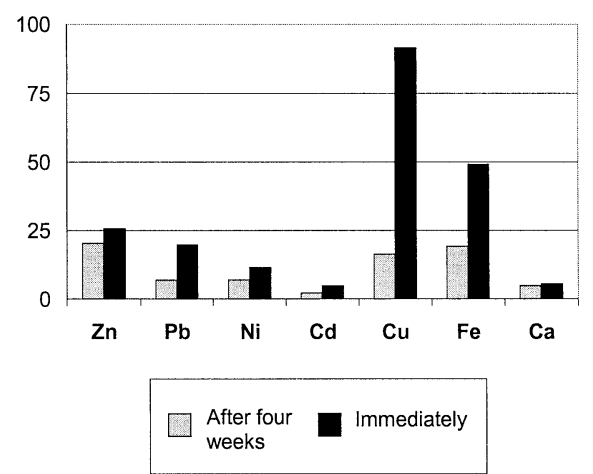

Fig. 1 Comparison between metal concentrations $(\mu \mathrm{g} / \mathrm{g}$, except $\mathrm{Ca}$ $\mathrm{mg} / \mathrm{g}$ ) found for SM\&T procedure step 1 (a) and step 2 (b) in solutions analyzed immediately or after 4 weeks from extraction. For graphic reasons, the $\mathrm{Zn}, \mathrm{Pb}$ and $\mathrm{Fe}$ values were divided by 10 .

- Biological (2): particles of definite morphology, animal or vegetal, usually Si-rich.

- Silicates (3): with a dominant Si peak, ascribed to inorganic $\mathrm{SiO}_{2}$.

- Aluminosilicates (4): with dominant Al and Si peaks.

- Fe-rich particles (5): aluminosilicate particles containing Fe.

- Ca-rich particles (6): aluminosilicate particles containing $\mathrm{Ca}$ and/or Mg.

- Iron oxides (7): particles with dominant Fe peak.

- Fe/Ca-rich particles (8): aluminosilicate particles containing $\mathrm{Fe}$ and $\mathrm{Ca}$ and/or $\mathrm{Mg}$.

Samples of non-treated CRM 601 and of residues of the extractions were suspended in Milli-Q water $\left(5 \mathrm{mg} \mathrm{l}^{-1}\right)$ and shaken for $24 \mathrm{~h}$. Successively, $2.5 \mathrm{ml}$ of the suspension was filtered through $0.45 \mu \mathrm{m}$ Millipore filters $(1 \mathrm{~cm}$ diameter $)$. The filters, once dried, were vacuum-coated with carbon.

The discarded solution was checked in order to exclude further metal release from the solid.

\section{Results and Discussion}

\section{Modified SM\&T procedure}

During preliminary experiments, which exactly followed the SM\&T procedure, we noted that samples not immediately analyzed had a lower concentration of all the metals, especially regarding step 2 (Fig. 1). This was probably due to the formation of colloidal hydroxides, because the $\mathrm{pH}$ of the extracts was about $4-5$. The only way to preserve samples was thus to add some strong acid to lower the $\mathrm{pH}$; consequently, the

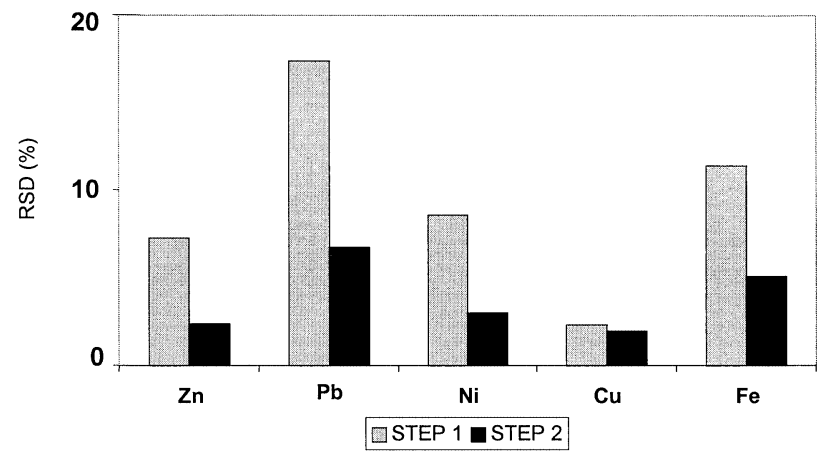

Fig. 2 Relative standard deviations (\%) calculated for monthly repeated analysis $(n=4)$ of the solutions from experiment 1 (steps 1 and 2 of SM\&T procedure).

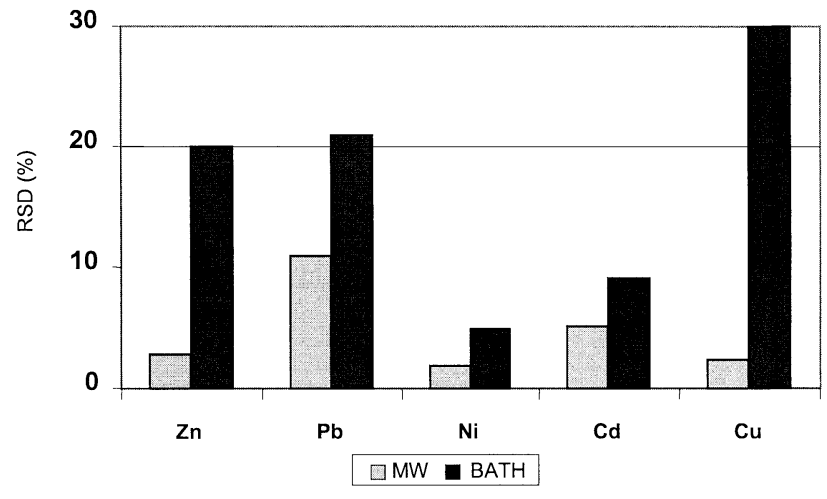

Fig. 3 Relative standard deviations (\%) obtained with the original SM\&T procedure step 3 (bath) and with the modified procedure step 3 (MW = microwaves)

solutions had to be made up to $50 \mathrm{ml}$, after the previous addition of the rinsing solutions of the residue.

To check correct storage, together with long-term instrumental analytical precision, we analyzed monthly the solutions from experiment 1 with every set of samples from experiments 2-4. As an example, the relative standard deviation calculated on the four values of steps 1 and 2 are shown in Fig. 2. The results are satisfying, with all of the RSD below $10 \%$, except for $\mathrm{Fe}$ (because of its small amount) and $\mathrm{Pb}$ in the first step.

The original SM\&T procedure, as regards step 3, foresees the addition of two aliquots of hydrogen peroxide, leaching at $85^{\circ} \mathrm{C}$ for $1 \mathrm{~h}$ (after $1 \mathrm{~h}$ at room temperature) and reduction to a small volume after each addition. Following this procedure, we obtained scarcely reproducible results, especially for $\mathrm{Zn}, \mathrm{Pb}$ and $\mathrm{Cd}$. Probably, when the sample is brought to a small volume, which, moreover, varies from one sample to another, this can cause high discrepancies, as noted even by other workers. ${ }^{20}$

After some unsuccessful attempts, we pointed out a different approach with the aid of ultrasound and microwave energy. This new step is as much as possible similar to the original. The amount of reagent is the same, and it is added in two aliquots; for the first hour the sample is kept at room temperature; after the reaction, ammonium acetate is added in order to extract the adsorbed metals on the oxidized surface of the sediment. The obtained results were encouraging, and more satisfying with respect to the traditional procedure, especially in terms of reproducibility, concerning the step 3 relative standard 
Table 2 Certified and obtained metal concentrations $(\mu \mathrm{g} / \mathrm{g})$ in the four experiments and the relative standard deviation calculated on the average values of each experiment (SM\&T procedure-step 1)

\begin{tabular}{ccccccc}
\hline & Certified & Experiment & Experiment & Experiment & Experiment & RSD\% \\
& & 1 & 2 & 3 & 4 & \\
\hline $\mathrm{Zn}$ & $264 \pm 5$ & $259 \pm 3$ & $263 \pm 2$ & $290 \pm 8$ & $261 \pm 12$ & 5.6 \\
$\mathrm{~Pb}$ & $2.68 \pm 0.35$ & $2.99 \pm 0.47$ & $3.21 \pm 0.61$ & $2.44 \pm 0.32$ & $2.69 \pm 0.35$ & 12 \\
$\mathrm{Ni}$ & $8.01 \pm 0.73$ & $8.73 \pm 1.19$ & $8.46 \pm 0.38$ & $8.40 \pm 1.00$ & $8.15 \pm 0.57$ & 2.8 \\
$\mathrm{Cd}$ & $4.14 \pm 0.23$ & $4.38 \pm 0.25$ & $3.87 \pm 0.44$ & $3.71 \pm 0.14$ & n.d. & 8.8 \\
$\mathrm{Cu}$ & $8.32 \pm 0.46^{\mathrm{a}}$ & $10.8 \pm 0.2$ & $12.0 \pm 0.4$ & $12.2 \pm 0.3$ & $10.8 \pm 0.5$ & 6.6 \\
\hline
\end{tabular}

a. Indicative value.

n.d.: not determined.

Table 3 Certified and obtained metal concentrations $(\mu \mathrm{g} / \mathrm{g})$ in the four experiments and the relative standard deviation calculated on the average values of each experiment (SM\&T procedure-step 2)

\begin{tabular}{|c|c|c|c|c|c|c|}
\hline & Certified & $\begin{array}{c}\text { Experiment } \\
1\end{array}$ & $\begin{array}{c}\text { Experiment } \\
2\end{array}$ & $\begin{array}{c}\text { Experiment } \\
3\end{array}$ & $\begin{array}{c}\text { Experiment } \\
4\end{array}$ & RSD \% \\
\hline $\mathrm{Zn}$ & & $228 \pm 3$ & $164 \pm 2$ & & $201 \pm 19$ & 13 \\
\hline $\mathrm{Pb}$ & $33.1 \pm 10.0^{\mathrm{a}}$ & a $\quad 162 \pm 3$ & $24.8 \pm 1.6$ & $42.1 \pm 9.51$ & $32.8 \pm 2.8$ & 26 \\
\hline $\mathrm{Ni}$ & $6.05 \pm 1.09$ & $9.41 \pm 0.42$ & $5.47 \pm 0.24$ & $5.66 \pm 0.40$ & $5.46 \pm 0.27$ & 2 \\
\hline $\mathrm{Cd}$ & $3.08 \pm 0.17$ & $5.50 \pm 0.26$ & $3.03 \pm 0.11$ & $4.14 \pm 0.20$ & n.d. & - \\
\hline $\mathrm{Cu}$ & $(1.7-10)$ & $50.0 \pm 1.0$ & $6.80 \pm 0.40$ & $7.1 \pm 0.63$ & $7.75 \pm 0.66$ & 7 \\
\hline
\end{tabular}

a. Indicative value.

( ) range given by SM\&T.

n.d.: not determined.

Table 4 Certified and obtained metal concentrations $(\mu \mathrm{g} / \mathrm{g})$ in the four experiments and the relative standard deviation calculated on the average values of each experiment (SM\&T procedure-step 3)

\begin{tabular}{|c|c|c|c|c|c|}
\hline Certified & $\begin{array}{c}\text { Experiment } \\
1\end{array}$ & $\begin{array}{c}\text { Experiment } \\
2\end{array}$ & $\begin{array}{c}\text { Experiment } \\
3\end{array}$ & $\begin{array}{c}\text { Experiment } \\
4\end{array}$ & $\mathrm{RSD} \%$ \\
\hline Zn $(98-277)$ & 128 & & & & 2.8 \\
\hline $\mathrm{Pb} \quad 109 \pm 13$ & 77. & & & & 11 \\
\hline Ni 8.55 & 6.42 & 40 & $9.36 \pm 0.22$ & $9.13 \pm$ & 1.8 \\
\hline $\mathrm{Cd} 1.8$ & 2.25 & $2.22 \pm 0.23$ & $2.11 \pm 0.23$ & $2.01 \pm 0.18$ & 5.2 \\
\hline $\mathrm{Cu}(80-193)$ & 92.6 & $144 \pm 8$ & $144 \pm 17$ & $150 \pm 12$ & 2.4 \\
\hline
\end{tabular}

( ) range given by SM\&T.

deviations obtained with the two different methods (Fig. 3).

The results of applying the entire modified scheme are shown in Tables $2-4$.

As regards step 1, the data show good accuracy for all of the elements considered, taking into account the respective confidence interval (95\% confidence level). As regards $\mathrm{Cu}$, it has to be noted that the value given by SM\&T is only indicative.

It is also evident that the in-set reproducibility (given by the confidence interval for the values of each experiment) is much better than the between-set reproducibility (given by RSD calculated on the 4 average values of each experiment), which is in any case very satisfying (RSD values below $10 \%$, except for $\mathrm{Pb} 12 \%)$.

For step 2, we can observe that there is great variability between experiment 1 and experiments $2-4$. It is evident that
$\mathrm{Zn}$

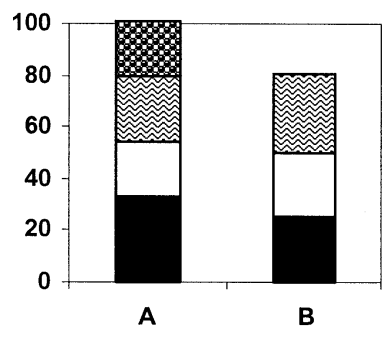

Cd

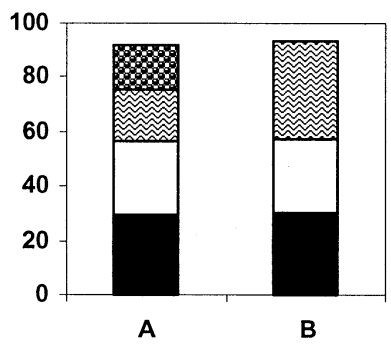

Ni

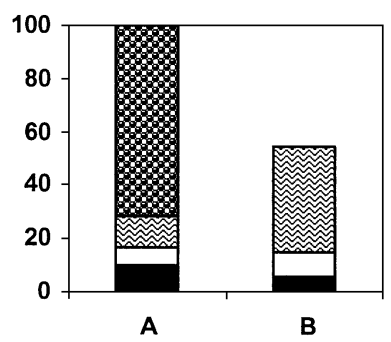

$\mathrm{Pb}$

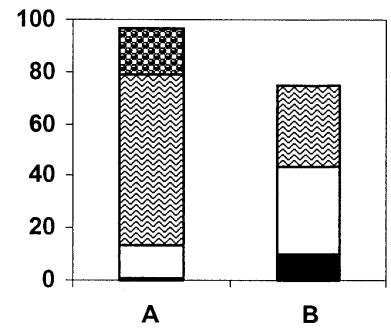

Cu

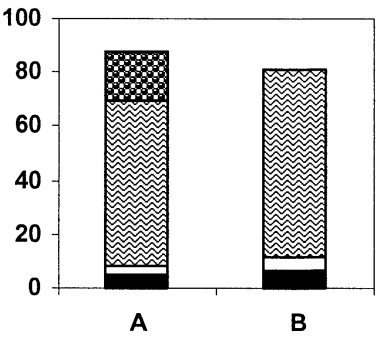

$\mathrm{Fe}$

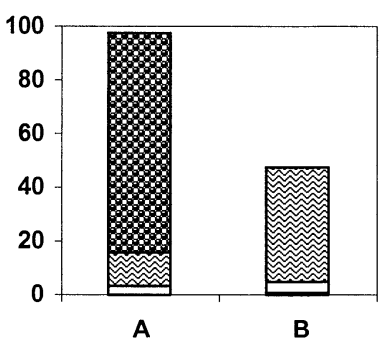

step $1 \square$ step 2 图 step 3 residue

Fig. 4 Metal partitioning (\% of the total amount) found for the $\mathrm{SM} \& \mathrm{~T}$ procedure (A) and for the previously used procedure (B).

in experiment 1 the chemical attack was more aggressive, probably due to a lower $\mathrm{pH}$ of the reagent. The observed trend is in accordance with the results found by Sahuquillo et al.,${ }^{21}$ who studied the influence of the hydroxylamine hydrochloride $\mathrm{pH}$ on the extraction variability.

Regarding experiments 2-4, we obtained a satisfying reproducibility, except for $\mathrm{Pb}$ ( $\mathrm{RSD} 26 \%$ ). The variability of this element is not surprising: because it is usually strongly bounded with substrates, it easily undergoes redistribution effects. ${ }^{22}$ Even the laboratories participating to the certification of CRM 601 observed "high spreads of the results for step 2 and step $3 " ; ;$ therefore, only an indicative value for step 2 is given. The accuracy is satisfying, considering that $\mathrm{Cu}$ was also not certified, but only a range of the values is available from the SM\&T report, and that our value is in good accordance with that found in the literature using the SM\&T scheme on the CRM 601.22

As regards step 3, even though our procedure is different from the protocol, a comparison of our results (experiments 2-4) with the certified and indicative values and ranges shows good accordance. Experiment 1, instead, presents considerably lower values: because step 2 of this experiment is too aggressive, it 
A
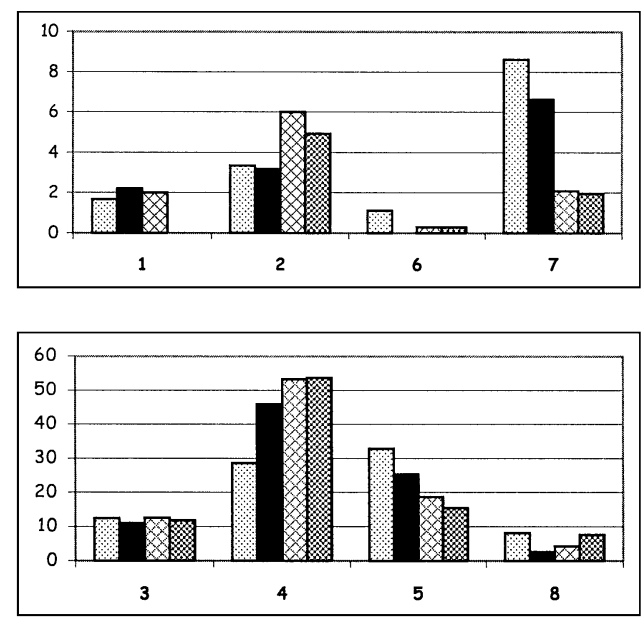

B
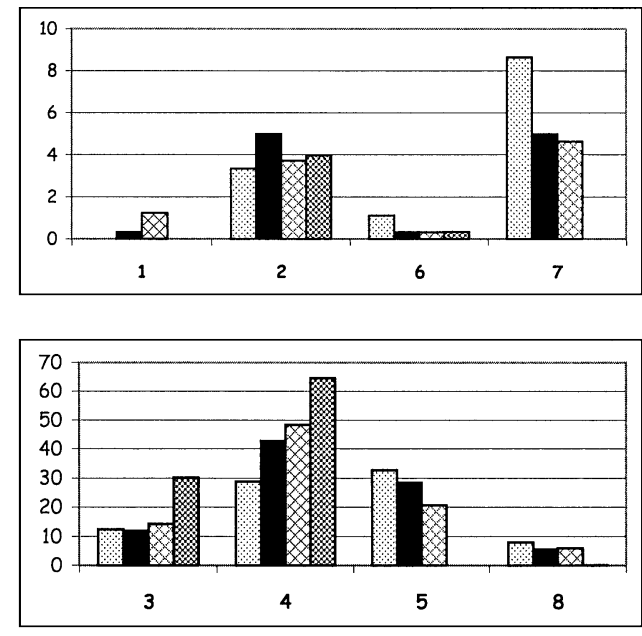

喅 601 STEP 1 囚 STEP 2 图 STEP 3

Fig. 5 Amount of particles (\%) present in every morphological group (see text for classification) in the non-treated sediment (601) and after each step of the SM\&T procedure (A) and previously used procedure (B).

leaches some metals even from the organic and/or sulfides fraction, suffering from a lack of selectivity.

Moreover, the data present a small in-set and between-set variability, confirming that the microwave procedure is sufficiently reproducible for speciation studies in the environmental field.

Even in this case, $\mathrm{Pb}$ is the only element which is much higher than the certified value and out of the reported range $(25-155$ mg kg-1). ${ }^{8}$ As already stated, lead suffers great variability due to its chemical characteristics. Moreover, its determination by ICP-AES is often influenced by spectral interference caused by aluminium, which is present to a certain extent in this extract.

\section{Comparison between the two extraction procedures}

The two procedures were applied to CRM 601. The use of a highly homogeneous material as a CRM guarantees that the amount of metals does not change from sample to sample, allowing one to attribute the differences found to the different methods. When the SM\&T procedure was used, determinations of the metal contents in the residual phase were also performed. Furthermore, the total concentrations of metals were determined on other aliquots of the CRM 601.

As can be seen from Fig. 4, the SM\&T procedure provides a satisfactory recovery. In fact, the sum of the three steps and of the residue, expressed as percentages of the total concentration, varies from 90 to $100 \%$. Comparing the partitioning of the metals among the two considered procedures (see Fig. 4), we can note a certain difference, as expected, especially regarding step 3. In fact, besides $\mathrm{Pb}$, which presents significative differences in every step, the other elements are all present in greater concentration only in the third step of procedure B. The nitric acid used in this scheme seems to be effectively too strong, and therefore not selective for the target phase, organic matter and sulfides. This fact is strongly outlined by SEM-EDX analysis, the results (average values of several experiments) of which are shown in Fig. 5, where the percentage of particles present after each extraction, and belonging to each of the eight morphological groups, is reported. We can note that, after step 3 of procedure $\mathrm{B}$, the only particles found in the solid residue are silicates (quartz and biogenic silica) or alumino-silicates; therefore, the elements previously bound to the crystalline lattice were completely leached by nitric acid. Moreover, SEMEDX analyses outline that even step 1 of this procedure seems to be too aggressive; in fact, it leaches a considerable amount of iron hydroxides, that should be extracted by the next step.

On the other hand, SEM analyses highlight that the SM\&T procedure is not only less aggressive, but even efficient enough. In fact, after step 3 there are no organic particles in the residue. After step 2 the Fe group $(5,7,8)$ decreases considerably and the same is true for $\mathrm{Ca}$ and $\mathrm{Mg}$ containing particles (6).

As regards $\mathrm{Pb}$, it is extracted in greater amount by procedure $\mathrm{B}$, especially regarding steps 1 and 2 (see Fig. 4). The reason for this behavior, also reported by other authors, ${ }^{22}$ can be related to the mentioned characteristics of lead, which can easily be readsorbed, and to its high tendency to form stable complexes with acetate. In fact, because of the lower concentration of acetate in step 1 and the absence of acetic acid in step 2 of the $\mathrm{SM} \& \mathrm{~T}$ procedure, lead complexes with acetate are formed to a lesser extent, or are not formed at all. As a consequence, redistribution is probably not completely avoided. On the other hand, procedure $\mathrm{B}$, which uses a high concentration of acetate in both steps, could leach $\mathrm{Pb}$, even from non-target phases.

Therefore, considering even the reproducibility problem illustrated above, the only reliable information obtainable with both extraction schemes is the amount of residual and nonresidual $\mathrm{Pb}$. The results concerning the speciation of $\mathrm{Pb}$ among the other phases should be treated with a certain caution, as outlined even by other authors. ${ }^{22}$

\section{Conclusions}

The original SM\&T selective extraction protocol was studied and subject to some modifications in order to enhance the reproducibility. In fact, the use of closed vessels in microwaves avoids the loss of analytes caused by the reaction with hydrogen peroxide and by the reduction to a small volume, while the acidification of the extracts guarantees a better conservation.

The modified procedure was then applied to a certified sediment to evaluate the analytical performance of the laboratory, outlining a high reliability of the results, with the exception of $\mathrm{Pb}$. The reproducibility for this element is not 
satisfying, especially in steps 2 and 3, probably caused by redistribution effects. Therefore, it could be necessary to improve in some way the extraction steps and/or to overcome the spectral interferences in $\mathrm{Pb}$ determination.

The comparison between the SM\&T procedure and the selective extraction scheme previously adopted in our laboratory outlined that the latter is too aggressive if the aim of the work concerns environmental studies, and therefore the determination of the heavy metals fraction characterized by the highest mobility and availability. This conclusion was drawn with the aid of microscopical techniques, which showed that, after procedure $\mathrm{B}$, all of the elements previously bound to the crystalline lattice were completely leached.

\section{Acknowledgements}

This work was financially supported by Fondi di Ateneo, MURST-COFIN 2000, Università di Genova.

\section{References}

1. C. M. Davidson, R. P. Thomas, S. E. McVey, R. Perala, D. Littlejohn, and A. M. Ure, Anal. Chim. Acta, 1994, 291, 277.

2. A. Kot and J. Namiesnik, Tr. Anal. Chem., 2000, 19, 69.

3. G. Rauret, Talanta, 1998, 46, 449.

4. G. D. Robinson, Chem. Geol., 1984/1985, 47, 97.

5. E. Tipping, N. B. Hetherington, J. Hilton, D. W. Thompson, E. Bowles, and J. Hamilton-Taylor, Anal. Chem., 1985, 57, 1944.

6. G. Rauret, R. Rubio, and J. F. Lopez-Sanchez, Int. J. Environ. Anal. Chem., 1989, 36, 69.

7. A. Tessier, P. G. C. Campbell, and M. Bisson, Anal. Chem.,
1979, 51,844 .

8. Ph. Quevauviller, G. Rauret, J. F. Lopez-Sanchez, R. Rubio, A. M. Ure, and H. Muntau, Report EUR 17554 EN European Commission, 1997, Bruxelles.

9. A. M. Ure, Ph. Quevauviller, H. Muntau, and B. Griepink, Int. J. Environ. Anal. Chem., 1993, 51, 135.

10. Ph. Quevauviller, G. Rauret, H. Muntau, A. M. Ure, R. Rubio, J. F. Lopez-Sanchez, H. D. Fiedler, and B. Griepink, Fresenius J. Anal. Chem., 1994, 349, 808.

11. S. K. Gupta and C. Aten, Int. J. Environ. Anal. Chem., 1993, 51, 25.

12. U. Förstner and J. Schoer, Environ. Tecnol. Lett., 1981, 1, 506.

13. M. Kersten and U. Förstner, Water Sci. Technol., 1986, 18, 121.

14. B. Cosma, F. Soggia, M. L. Abelmoschi, and R. Frache, Int. J. Environ. Anal. Chem., 1994, 55, 121.

15. L. Zaggia, R. Zonta, S. Miserocchi, and E. Argese, Rapporti e studi, Istituto Veneto di Scienze Lettere ed Arti XII, 1995, 425.

16. P. C. Bernard, R. Van Grieken, and L. Brugmann, Mar. Chem., 1989, 26, 155.

17. A. Bellanca, S. Hauser, R. Neri, and B. Palumbo, Sci. Total Environ., 1996, 193, 57.

18. F. Baffi, M. Ravera, C. Ianni, F. Soggia, and E. Magi, Anal. Chim. Acta, 1995, 306, 149.

19. F. Baffi, C. Ianni, M. Ravera, F. Soggia, and E. Magi, Anal. Chim. Acta, 1998, 360, 27.

20. B. Marin, M. Valladon, M. Polve, and A. Monaco, Anal. Chim. Acta, 1997, 342, 91.

21. A. Sahuquillo, J. F. Lopez-Sanchez, R. Rubio, G. Rauret, R. P. Thomas, C. M. Davidson, and A. M. Ure, Anal. Chim. Acta, 1999, 382, 317.

22. Z. Mester, C. Cremisini, E. Ghiara, and R. Morabito, Anal. Chim. Acta, 1998, 359, 133. 